\title{
PENGEMBANGAN SISTEM INFORMASI PREVENTIVE MAINTENANCE PADA PT. MEDAN TROPICAL CANNING
}

\author{
Erikson Damanik \\ Komputerisasi Akuntansi, Politeknik Bisnis Indonesia \\ email: damanik.1969@gmail.com
}

\begin{abstract}
Abstrack
PT. Medan Tropical Canning is a company engaged in the production and export of aquaculture materials and marine catches, such as shrimp, fish, and so on. PT. Medan Tropical Canning manually monitors and maintains production machinery such as calculation of maintenance schedules and replacement of spare parts contained in production machinery. Frequent occurrences of errors in the calculation of maintenance scheduling and replacement of spare parts cause disruption of production activities. To deal with the problem, the authors propose a computerized information system using the STRADIS system development methodology. This information system is a program developed using the Microsoft Visual Basic 2005 programming language, database using Microsoft SQL Server 2000, and Business Objects Crystal Report 10 for report design. With the completion of the developed system, the data inputted will be processed with a database management system so that it can help monitor and maintain production machines and make reports faster and more accurate. The results of this computerized preventive maintenance information system are expected to benefit the company.
\end{abstract}

Kata Kunci : Stradis, Visual Basic 2005, SQL Server 2000, Crystal Report

\section{PENDAHULUAN}

Produksi adalah suatu kegiatan yang cukup penting di dalam perusahaan. Apabila kegiatan produksi dalam suatu perusahaan ini terhenti, maka kegiatan dalam perusahaan tersebut akan ikut terhenti pula karenanya. Oleh sebab itu pemeliharaan mesin-mesin produksi mesti dilakukan secara teratur, dengan melakukan penjadwalan dan pemeriksaan suku cadang mesin yang akan diganti. Dengan adanya sistem informasi preventive maintenance secara komputerisasi dapat membantu perusahaan dalam memonitoring dan memelihara mesin produksi.

PT. Medan Tropical Canning adalah perusahaan yang bergerak di bidang produksi dan ekspor bahan-bahan hasil pertambakan dan hasil tangkap laut, seperti udang, ikan, dan sebagainya yang dikemas di dalam kaleng maupun bungkusan plastik. Pada saat ini PT. Medan Tropical Canning melakukan monitoring dan pemeliharaan mesin produksi secara manual seperti perhitungan jadwal perawatan dan penggantian suku cadang yang terdapat pada mesin produksi. Hal ini menyebabkan pembuatan laporan pemeliharaan mesin produksi memerlukan waktu yang relatif lama dan sering terjadi kesilapan dalam perhitungan penjadwalan perawatan dan penggantian suku cadang yang menyebabkan terganggunya kegiatan produksi.

Untuk memperlancar kegiatan operasional perusahaan tersebut, diperlukan sebuah sistem informasi yang dapat membantu monitoring dan pemeliharaan mesin produksi.

Sistem informasi merupakan suatu alat untuk menyajikan informasi sedemikian rupa sehingga bermanfaat bagi penerimanya [1].

Penggunaan Sistem informasi sudah banyak dimanfaatkan untuk membantu memperlancar kegiatan suatu perusahaan/ institusi [2]-[5], [6], [7], [8], [9].

Oleh karena itu, untuk mengatasi masalah tersebut di atas, maka di kembangkan sebuah Sistem Informasi Preventive Maintenance pada PT. Medan Tropical Canning". Sistem informasi ini mampu untuk membantu mengolah pendataan mesin produksi, suku cadang dan penggunaan mesin harian. Selain itu, Sistem Informasi ini juga dapat digunakan untuk pembuatan laporan jadwal perawatan dan penggantian suku cadang, laporan pembelian, laporan persediaan, dan laporan pengembalian suku cadang. 
Dengan adanya sistem ini, monitoring dan pemeliharaan mesin produksi dapat dilakukan dengan mudah, penjadwalan pemeliharaan dan penggantian suku cadang tepat waktu dan akurat, kegiatan produksi dapat berjalan dengan lancar, pembuatan laporan dapat dihasilkan dengan cepat.

\section{METODOLOGI PENELITIAN}

Metodologi pengembangan sistem yang digunakan adalah STRADIS (Structured Analysis, Design, and Implementation of Information Systems). Tahapan metode STRADIS yang digunakan adalah :

1. Fase Studi Awal

Pada fase ini dilakukan :

a. Pengumpulan data dengan menggunakan studi lapangan dan studi perpustakaan, serta melakukan tinjauan organisasi perusahaan.

b. Pengkajian dokumentasi yaitu dokumentasi keluaran dan dokumentasi masukan sistem berjalan.

c. Konstruksi diagram konteks pendahuluan sistem berjalan.

2. Fase Studi Detail

Pada fase ini dilakukan :

a. Definisi pengguna dan unit yang terkait dengan sistem baru.

b. Konstruksi DFD level 0 sistem berjalan.

c. Identifikasi masalah.

3. Fase Definisi dan Rancangan Solusi Alternatif

Pada fase ini dilakukan :

a. Identifikasi kebutuhan perusahaan.

b. Merancang diagram konteks sistem usulan.

4. Fase Rancangan Fisik

Pada fase ini dilakukan :

a. Marancang DFD level 0 dan DFD level 1 sistem usulan.

b. Merancang kamus data.

c. Merancang keluaran dengan Business Objects Crystal Report 10 dan masukan dengan Microsoft Visual Basic 2005.

d. Merancang basis data dengan menggunakan teknik normalisasi, struktur tabel database dan relasi antar tabel dengan Microsoft SQL Server 2000.

e. Merancang user interface yang berisi menu dan sub-menu program.
Setelah semua tahapan di STRADIS dilakukan, penulis akan mengembangkan aplikasi berdasarkan rancangan yang telah diperoleh.

\section{HASIL DAN PEMBAHASAN}

\subsection{Hasil}

\subsubsection{Menu}

Pada saat program dijalankan, tampilan awalnya terlihat seperti pada Gambar 3.1 berikut ini :

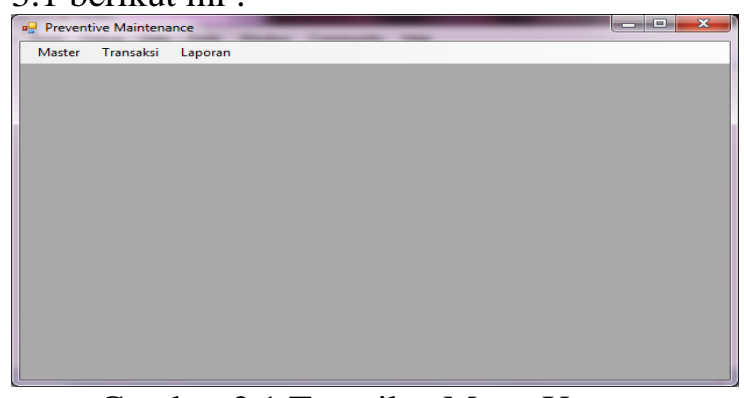

Gambar 3.1 Tampilan Menu Utama

\section{Menu Master}

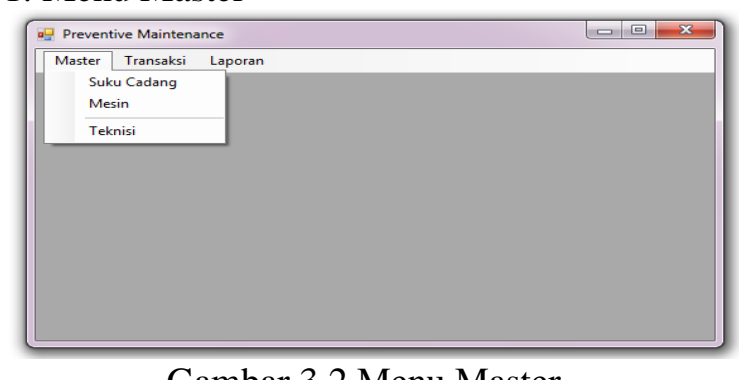

Gambar 3.2 Menu Master

2. Menu Transaksi

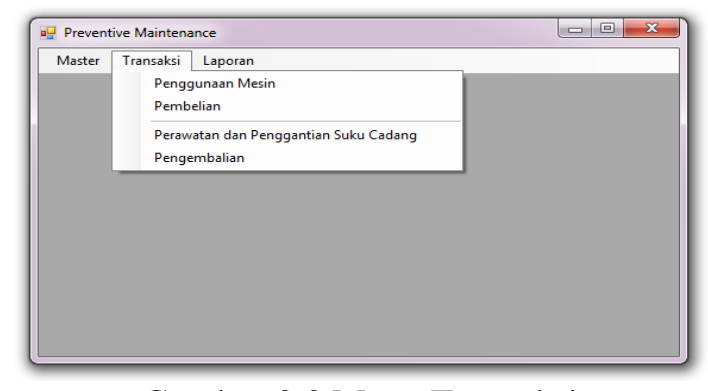

Gambar 3.3 Menu Transaksi

\section{Menu Laporan}

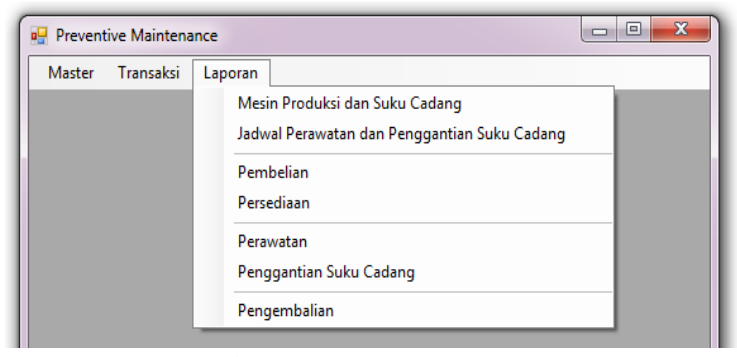

Gambar 3.4 Menu Laporan 


\subsubsection{Input Sistem}

Program sistem informasi preventive maintenance terdapat beberapa fungsi untuk melakukan input sistem, yaitu :

\section{Suku Cadang}

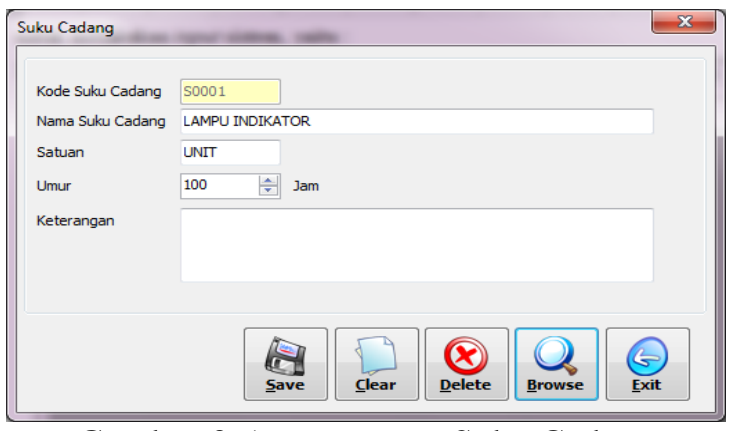

Gambar 3.5 Form Input Suku Cadang



Gambar 3.6 Form Browse Suku Cadang

2. Mesin Produksi

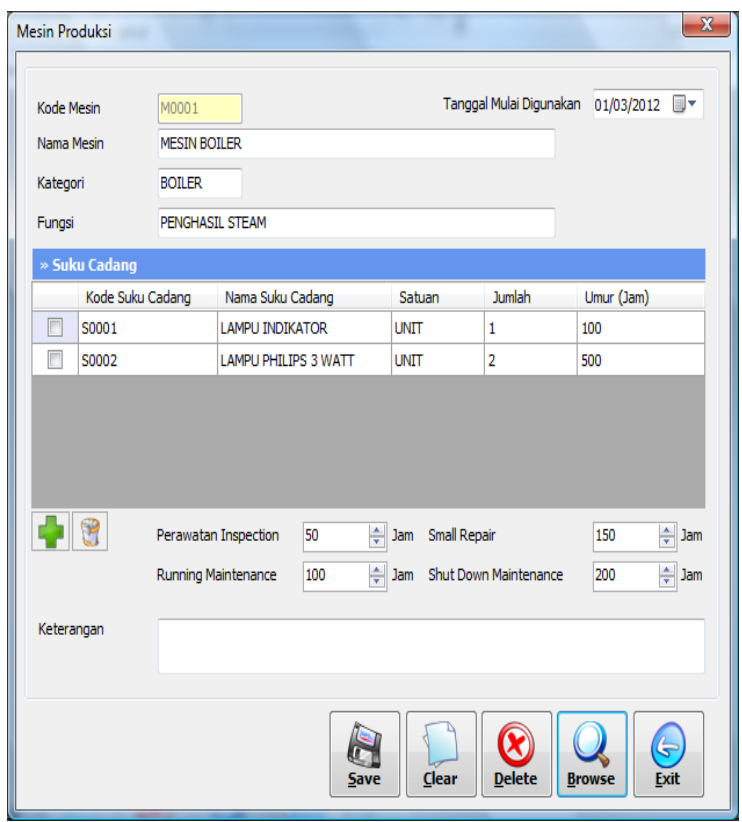

Gambar 3.7 Form Input Mesin Produksi

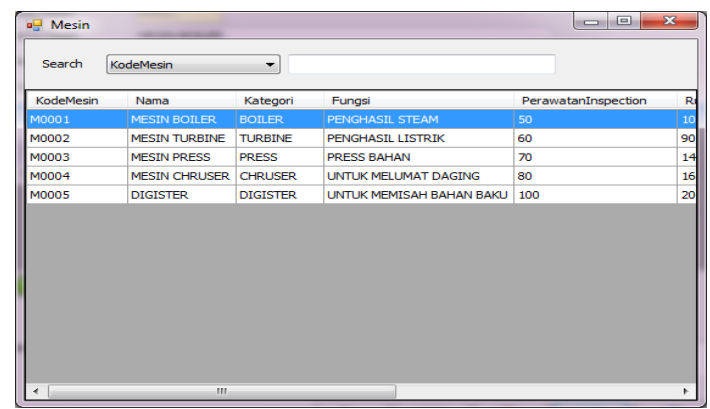

Gambar 3.8 Form Browse Mesin Produksi

3. Teknisi



Gambar 3.9 Form Input Teknisi

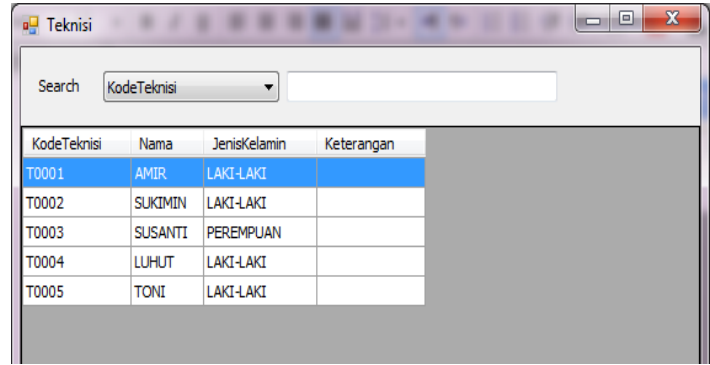

Gambar 3.10 Form Browse Teknisi

\section{Penggunaan Mesin Harian}

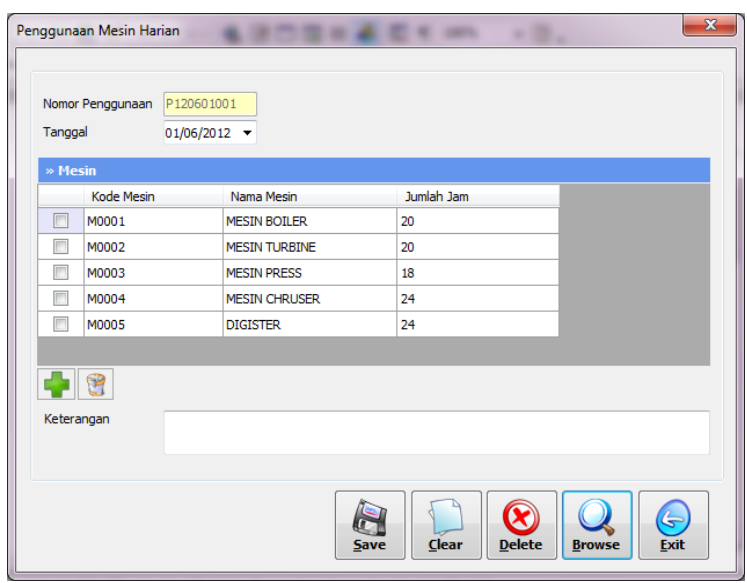

Gambar 3.11 Form Input Penggunaan Mesin Harian 




Gambar 3.12 Form Browse Penggunaan Mesin Harian

\section{Pembelian}

Form input pembelian dapat dilihat pada Gambar 3.13 berikut ini :

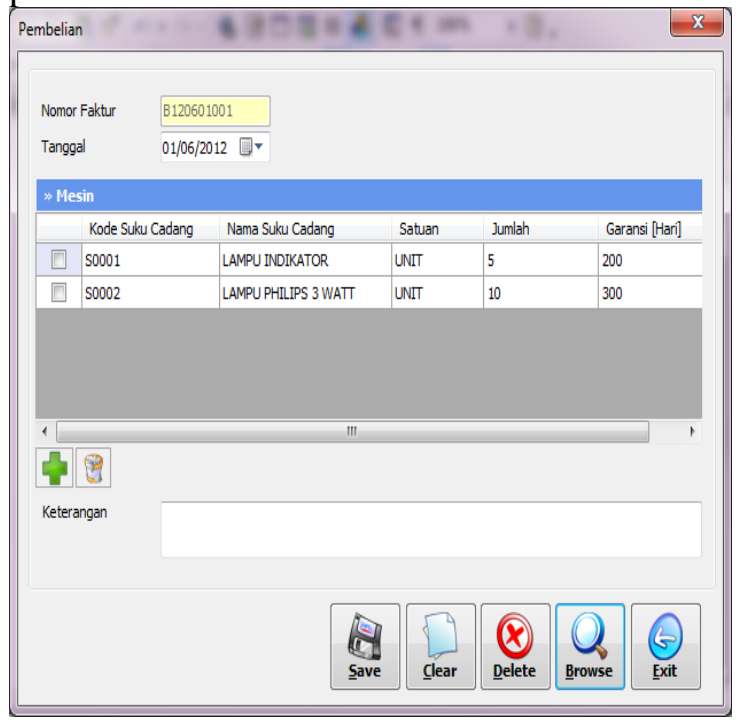

Gambar 3.13 Form Input Pembelian

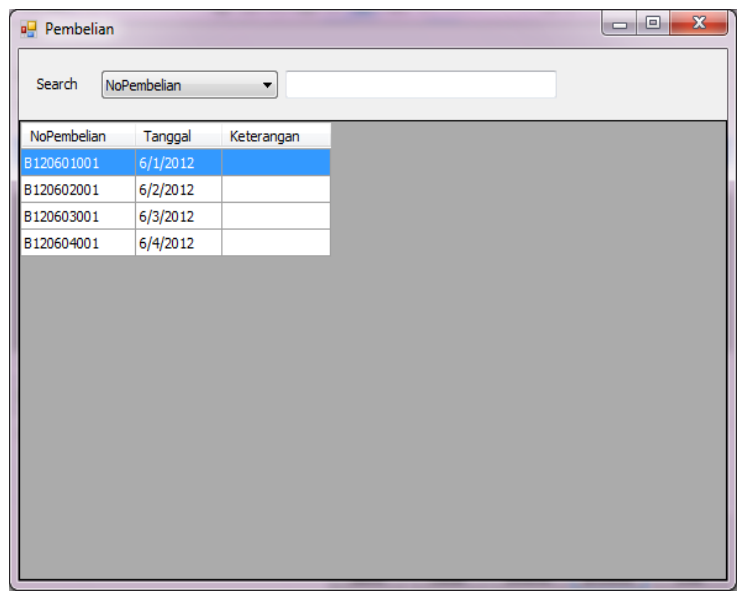

Gambar 3.14 Form Browse Pembelian
6. Perawatan dan Penggantian Suku Cadang

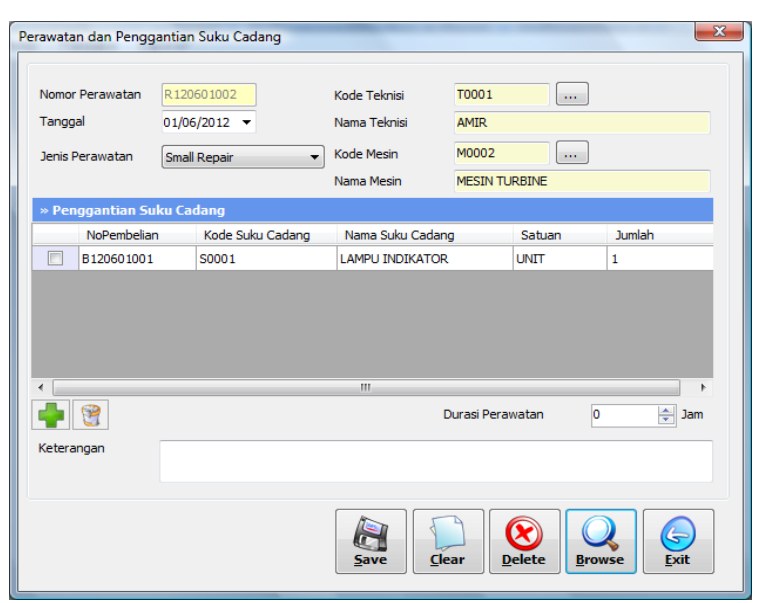

Gambar 3.15 Form Input Perawatan dan Penggantian Suku Cadang



Gambar 3.16 Form Browse Perawatan dan Penggantian Suku Cadang

\section{Pengembalian}

Form input pengembalian dapat dilihat pada Gambar 3.17 berikut ini :



Gambar 3.17 Form Input Pengembalian 


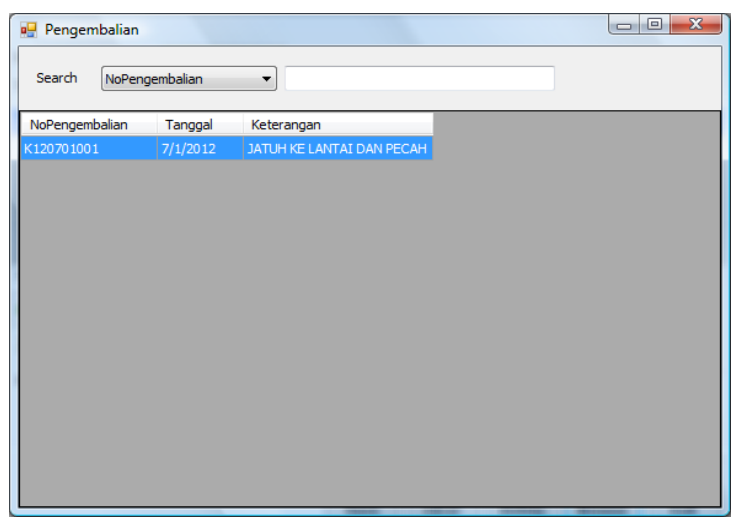

Gambar 3.18 Form Browse Pengembalian

\subsubsection{Output Sistem}

Program sistem informasi preventive maintenance terdapat beberapa fungsi untuk melakukan output sistem, yaitu :

\section{Laporan Mesin Produksi dan Suku Cadang}

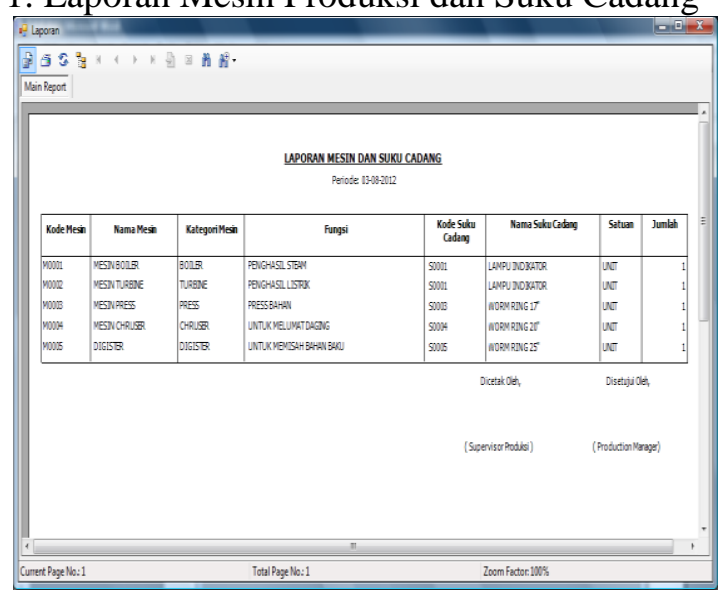

Gambar 3.19 Laporan Mesin Produksi dan Suku Cadang

2. Laporan Perawatan dan Penggantian Suku Cadang



Gambar 3.20 Laporan Perawatan dan Penggantian Suku Cadang
3. Laporan Pembelian

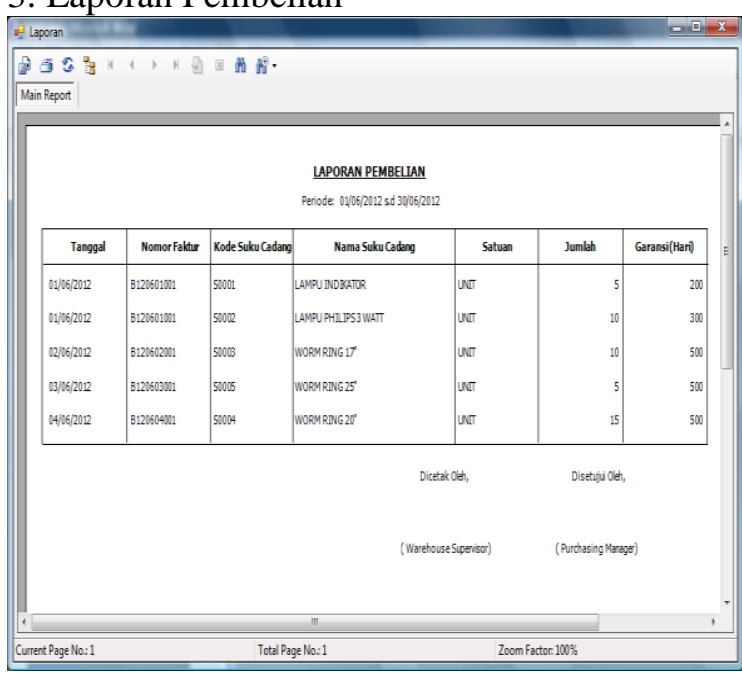

Gambar 3.21 Laporan Pembelian

4. Laporan Persediaan

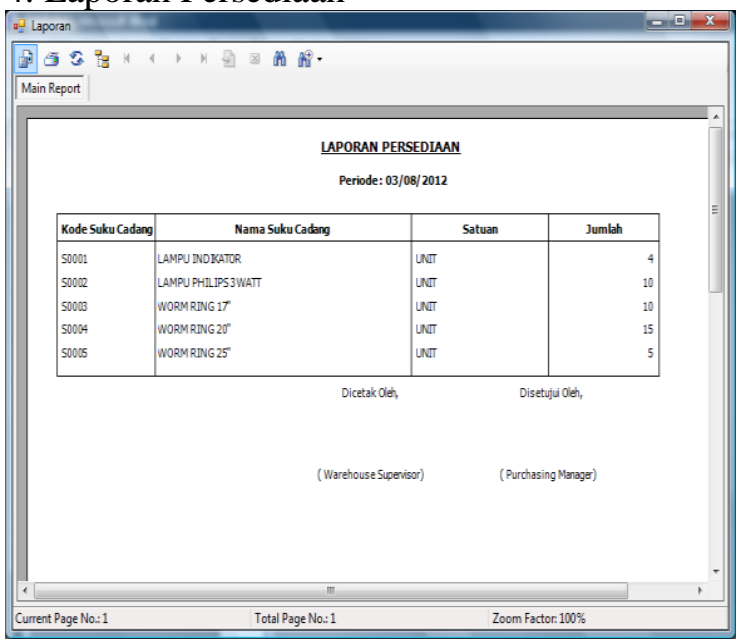

Gambar 3.22 Laporan Persediaan

5. Laporan Perawatan



Gambar 3.23 Laporan Perawatan 
6. Laporan Penggantian Suku Cadang

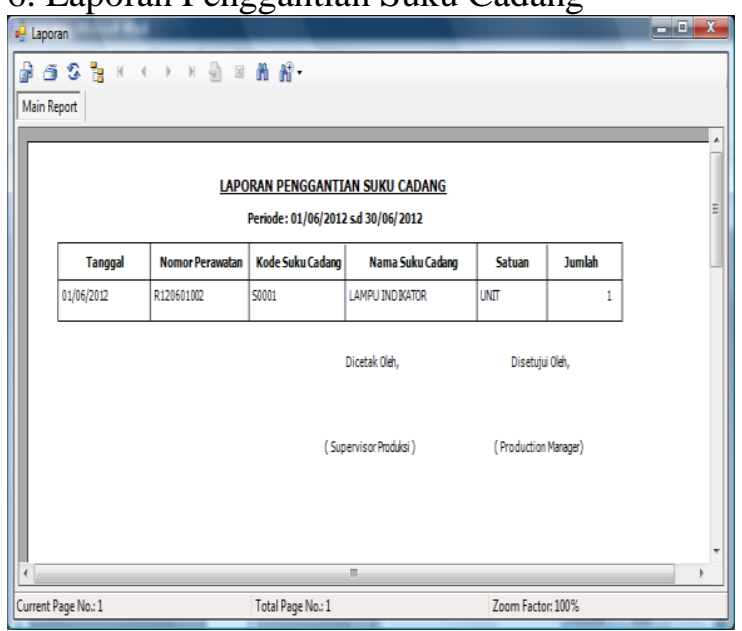

Gambar 3.24 Laporan Penggantian Suku Cadang

7. Laporan Pengembalian Suku Cadang

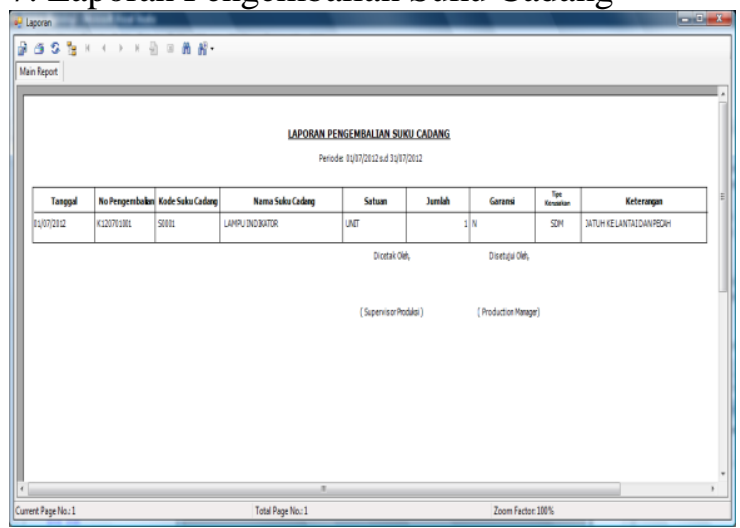

Gambar 3.25 Laporan Pengembalian Suku Cadang

\section{KESIMPULAN DAN SARAN Kesimpulan}

Adapun kesimpulan yang didapatkan penulis setelah menyelesaikan tugas akhir ini adalah sebagai berikut :

1. Sistem informasi yang berjalan memerlukan waktu yang cukup lama di dalam pembuatan laporan yang dibutuhkan.

2. Sistem informasi yang dirancang dapat menghasilkan jadwal perawatan dan penggantian suku cadang secara otomatis.

3. Sistem informasi yang dirancang dapat menghasilkan laporan mesin produksi dan suku cadang, laporan jadwal perawatan dan penggantian suku cadang, laporan pembelian, laporan persediaan, laporan perawatan, laporan penggantian suku cadang, laporan pengembalian suku cadang dengan cepat.

\section{REFERENSI}

[1] V. M. M. Siregar, "Sistem Informasi Pembelian Dan Penjualan Pakaian Pada Galoenk Distro Pematangsiantar," JurTI (Jurnal Teknol. Informasi), vol. 1, no. 2, pp. 219-227, 2017.

[2] V. M. M. Siregar, H. Sugara, and I. M. Siregar, "Perancangan Sistem Informasi Pendataan Barang Pada PT. Serdang Hulu," J. Comput. Bisnis, vol. 12, no. 2, pp. 111-117, 2018.

[3] H. Nurdiansyah and A. Mulyawan, "Perancangan Sistem Persediaan Barang Pada Bagian Penyimpanan Barang Di Cabang Pelayanan Dinas Pendapatan Daerah Provinsi Wilayah Kota Bandung III," J. Comput. Bisnis, vol. 9, no. 1, pp. 1-11, 2015.

[4] S. Mukaromah and D. Rosadi, "PERANCANGAN APLIKASI ECOMMERCE (STUDI KASUS: DISTRIBUTOR COKLAT BANDUNG)," J. Comput. Bisnis, vol. 9, no. 1, pp. 58-72, 2015.

[5] M. R. Ridha, "Perancangan Sistem Infomasi Pengolahan Data Kuliah Kerja Usaha Dan Penelitian (Studi Kasus : Program Studi Sistem Informasi Universitas Islam Indragiri)," SISTEMASI, vol. 2, no. 4, pp. 14-26, 2013.

[6] V. Sihombing, "Sistem Informasi Penjualan Mobil Suzuki Di Dealer Bagan Batu," SISTEMASI, vol. 7, no. 2, pp. 113-119, 2018.

[7] A. Ardian, I. Purnama, and V. Sihombing, "Perancangan Aplikasi Pengolah Data Siswa Berbasis Android (Studi Kasus: Mis Nurul Huda Labuhan Batu Selatan)," Pengabdi. Masy. Ika Bina En Pabolo, vol. 1, no. 1, pp. 40-53, 2019.

[8] W. Purba, S. Aisyah, and S. P. Tamba, "Perancangan Sistem Pakar Diagnosa Penyakit Mata Katarak Menggunakan Konsep Metode Runut Mundur," JUSIKOM PRIMA (Junal Sist. Inf. Ilmu Komput. Prima), vol. 1, no. 1, 2017.

[9] Fricles Ariwisanto Sianturi, "Aplikasi Pembelajaran Penjaskes Olahraga Basket Menggunakan Metode Computer Assisted Instruction (CAI)," J. Inform. Pelita Nusant., vol. 1, no. 1, pp. 47-52, 2016. 